\title{
Sirolimus for Kaposiform Hemangioendothelioma and Kasabach-Merritt Phenomenon in a Neonate
}

\author{
Trevor B. Cabrera, MD ${ }^{1}$ Allison L. Speer, MD ${ }^{2}$ Matthew R. Greives, MD 3 Donna A. Goff, MD \\ Neethu M. Menon, MD ${ }^{5}$ Eric W. Reynolds, MD, MPH
}

${ }^{1}$ Department of Pediatrics, University of Texas Health Science Center at Houston/McGovern Medical School, Houston, Texas

${ }^{2}$ Department of Pediatric Surgery, University of Texas Health Science Center at Houston/McGovern Medical School, Houston, Texas

${ }^{3}$ Department of Pediatric Plastic Surgery, University of Texas Health Science Center at Houston/McGovern Medical School, Houston, Texas

${ }^{4}$ Department of Pediatric Cardiology, University of Texas Health Science Center at Houston/McGovern Medical School, Houston, Texas

${ }^{5}$ Department of Pediatric Hematology, University of Texas Health Science Center at Houston/McGovern Medical School, Houston, Texas

${ }^{6}$ Department of Neonatal/Perinatal Medicine, University of Texas Health Science Center at Houston/McGovern Medical School, Houston, Texas

Address for correspondence Trevor B. Cabrera, MD, Department of Pediatrics, University of Texas Health Science Center at Houston, McGovern Medical School, 6431 Fannin St. MSB 3.151, Houston, TX 77030 (e-mail: trevor.cabrera@gmail.com).

Am J Perinatol Rep 2020;10:e390-e394.

\author{
Abstract \\ Keywords \\ - kaposiform \\ hemangioen- \\ dothelioma \\ - Kasabach-Merritt \\ phenomenon \\ - sirolimus
}

We present a case of a neonate born with kaposiform hemangioendothelioma (KHE), complicated by Kasabach-Merritt phenomenon (KMP) and other serious conditions, who was successfully treated with sirolimus. In addition to complications from thrombocytopenia and fluid overload, during the course of therapy, our patient experienced supratherapeutic drug levels at the commonly accepted starting dose of sirolimus. Patients with KHE and KMP should be closely monitored for potential complications of both the initial disease and unexpected side effects of treatments.
Kaposiform hemangioendothelioma (KHE) is a rare infiltrative vascular tumor typically diagnosed during infancy. Over $70 \%$ of patients with KHE will develop Kasabach-Merritt phenomenon (KMP), a potentially life-threatening consumptive coagulopathy. We present the case of an infant with KHE and KMP successfully treated with sirolimus.

\section{Case Presentation}

The patient was the product of a 34 2/7 week gestation born to a 27-year-old Hispanic female who was G2, P0010, A-pos, rapid plasma reagin: nonreactive, HepB: negative, Rubella: nonimmune and group B Streptococcus: unknown. The pregnancy was complicated by intrauterine growth restriction (IUGR), reversed end diastolic flow, and a dilated vena cava on prenatal ultrasound. The mother was treated with betamethasone in preparation for preterm delivery. The mother's medical history included surgical repair of a congenital heart disease at the age of 11 in Cuba. However, it was unclear what specific defect she had ("a hole in the heart," presumably an atrial or ventricular septal defect). The baby was delivered by scheduled cesarean section due to IUGR and reversed end diastolic flow. Apgar scores were 9 and 9 and birth weight was $1,575 \mathrm{~g}$. The NICU team attended the received

July 6,2020

accepted after revision

August 21, 2020
DOI https://doi.org/

10.1055/s-0040-1718901. ISSN 2157-6998.
Copyright $\odot 2020$ by Thieme Medical

Publishers, Inc., 333 Seventh Avenue, New York, NY 10001, USA. Tel: +1(212) 760-0888.
License terms

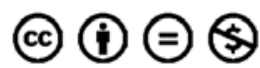




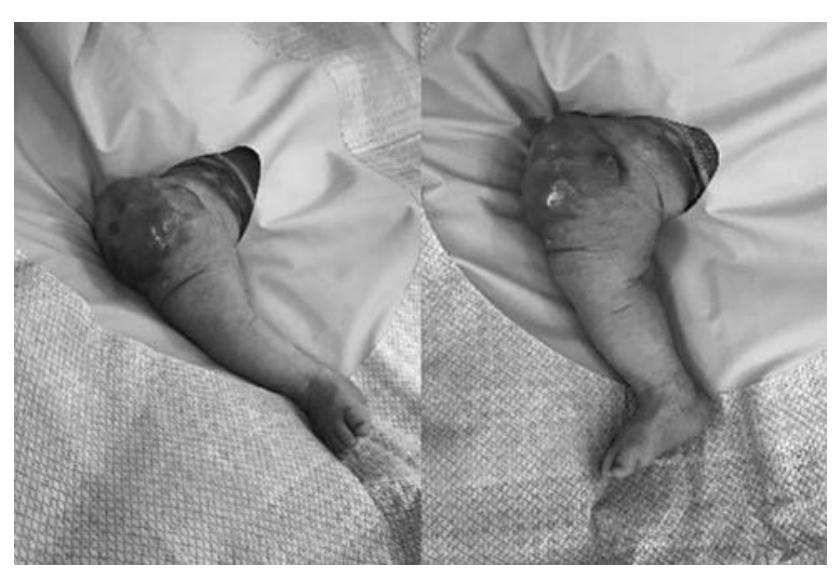

Fig. 1 Appearance of the kaposiform hemangioendothelioma lesion of the anterior right thigh of the patient at excisional biopsy on day of life 3 .

delivery due to prenatal concern for a prenatal finding of a dilated vena cava of unknown significance. The baby required routine interventions at delivery. The baby was transferred to the NICU for evaluation. Additionally, his initial exam found a large vascular tumor on the anterior right thigh (-Fig. 1), but was otherwise normal.

Upon arrival in the NICU, the baby was stable on room air with normal vital signs. An echocardiogram showed normal cardiac anatomy and function for age. Initial laboratories were significant for a white blood cell count of 9,100 (56\% neutrophils and $4 \%$ bands) and a hematocrit of $36.4 \%$. The baby had findings consistent with KMP. His platelet count was $13,000 / \mu \mathrm{L}$. Coagulation studies were significant for prothrombin time of 27.4 seconds, activated partial thromboplastin time of 42.1 seconds, international normalized ratio of 2.62 , thrombin of 24.9 , fibrinogen $<60 \mathrm{mg} / \mathrm{dL}$, and D-Dimer $16.05 \mathrm{ng} / \mathrm{mL}$. He required multiple transfusions over the first 2.5 weeks of life to control his symptoms of KMP, including 6 platelet transfusions, 12 fresh frozen plasma infusions, 2 cryoprecipitate infusions, and 6 packed red cell transfusions.

Ultrasound of the right leg found an echogenic mass measuring $8.4 \times 5.4 \times .7 .0 \mathrm{~cm}$ within the right anterior thigh containing arterial and venous waveforms. There was no arterial or deep vein thrombosis. On day of life 2, magnetic resonance imaging (MRI) of the lesion showed a contrast enhanced lesion with multiple vascular channels concerning for a vascular tumor, with no fascial involvement or arteriovenous malformations (AVM). Abdominal ultrasound was normal. A brain ultrasound was significant for right grade 4 and left grade 2 intraventricular hemorrhage (IVH). An incisional biopsy of the lesion was performed on day of life 3 which showed a spindle cell neoplasm with neovascular channels and hemorrhage with immunohistochemistry negative for human herpesvirus 8 and glucose transporter 1 , and positive for CD31, CD34, and D2-40, confirming the diagnosis of KHE. On day of life 4, sirolimus was initiated at a standard dose of $0.8 \mathrm{mg} / \mathrm{m}^{2}$ per dose twice a day, along with methylprednisolone at a dose of $1 \mathrm{mg} / \mathrm{kg}$ per dose twice a day.
On day of life 5 , the baby developed severe anasarca and acidosis and required intubation and mechanical ventilation. An echocardiogram on day of life 6 showed severely depressed biventricular function with an ejection fraction of $11 \%$, moderate mitral and tricuspid regurgitation, reversed flow in the pulmonary veins, and dilation of the inferior vena cava, left and right atria, and left ventricle without pericardial effusion. He received multiple medications including dopamine, milrinone, furosemide, digoxin, and captopril and was extubated on day of life 12 . A repeat echocardiogram on day of life 13 showed normal heart function. On day of life 15 , the sirolimus level was unmeasurably high $(>30 \mathrm{ng} / \mathrm{mL})$, well above the target trough range of 10 to $15 \mathrm{ng} / \mathrm{mL}$. Therapy was paused for 5 days and restarted at $0.4 \mathrm{mg} / \mathrm{m}^{2}$ per dose twice a day. He remained in the therapeutic range of 10 to $15 \mathrm{ng} / \mathrm{mL}$ thereafter for the duration of his treatment with a decrease in the size of the lesion and resolution of KMP within 4 weeks of starting therapy (-Fig. 2). He was discharged from the hospital on day of life 53 .

Additionally, given the initial findings of IVH on a brain ultrasound at day of life 2, an MRI was performed on day of life 23 showing evolution of encephalomalacia of the temporal and occipital lobes with multiple small foci of hemorrhage scattered throughout the left cerebellum and periventricular regions. There was bilateral cerebral white matter injury with significant cystic changes. No evidence was found for posthemorrhagic hydrocephalus.

The baby continued to show decreased size of the lesion at outpatient follow-up on sirolimus therapy at 2 and 3 months (-Fig. 3). He had no significant side effects from his treatment and has remained at therapeutic levels. Repeat echocardiograms continued to show normal heart function. An MRI performed at 5 months of life showed contraction of the right occipital hematoma with evolved encephalomalacia without any new areas of bleeding. Unfortunately, he was lost to follow-up due to familial relocation at 6 months of life. Despite treatment of KHE being considered successful, we remain concerned for his cognitive potential due to his complicated course.

\section{Discussion}

KHE, first described in 1993, is characterized by a violaceous cutaneous lesion with ill-defined borders occurring in childhood and infancy. ${ }^{1}$ It is a rare infiltrative vascular tumor with a prevalence of $\sim 0.91$ per 100,000 and incidence of less than 1 per 1 million children. The majority (60\%) occurs in infants and neonates. ${ }^{2}$ Per a revised classification system by the International Society for the Study of Vascular Anomalies in 2018, KHE has been designated as a locally aggressive or borderline vascular tumor. ${ }^{3}$ Lesions most commonly affect the extremities. Eighty percent have both cutaneous and deep involvement and up to $30 \%$ have extension into multiple anatomic regions. No multifocal lesions or metastatic spread have been reported. Unlike infantile or congenital hemangiomas, KHE does not involute spontaneously. Importantly, KHE is not an AVM and thus does not spontaneously increase the risk of high-output heart failure. Diagnostic 


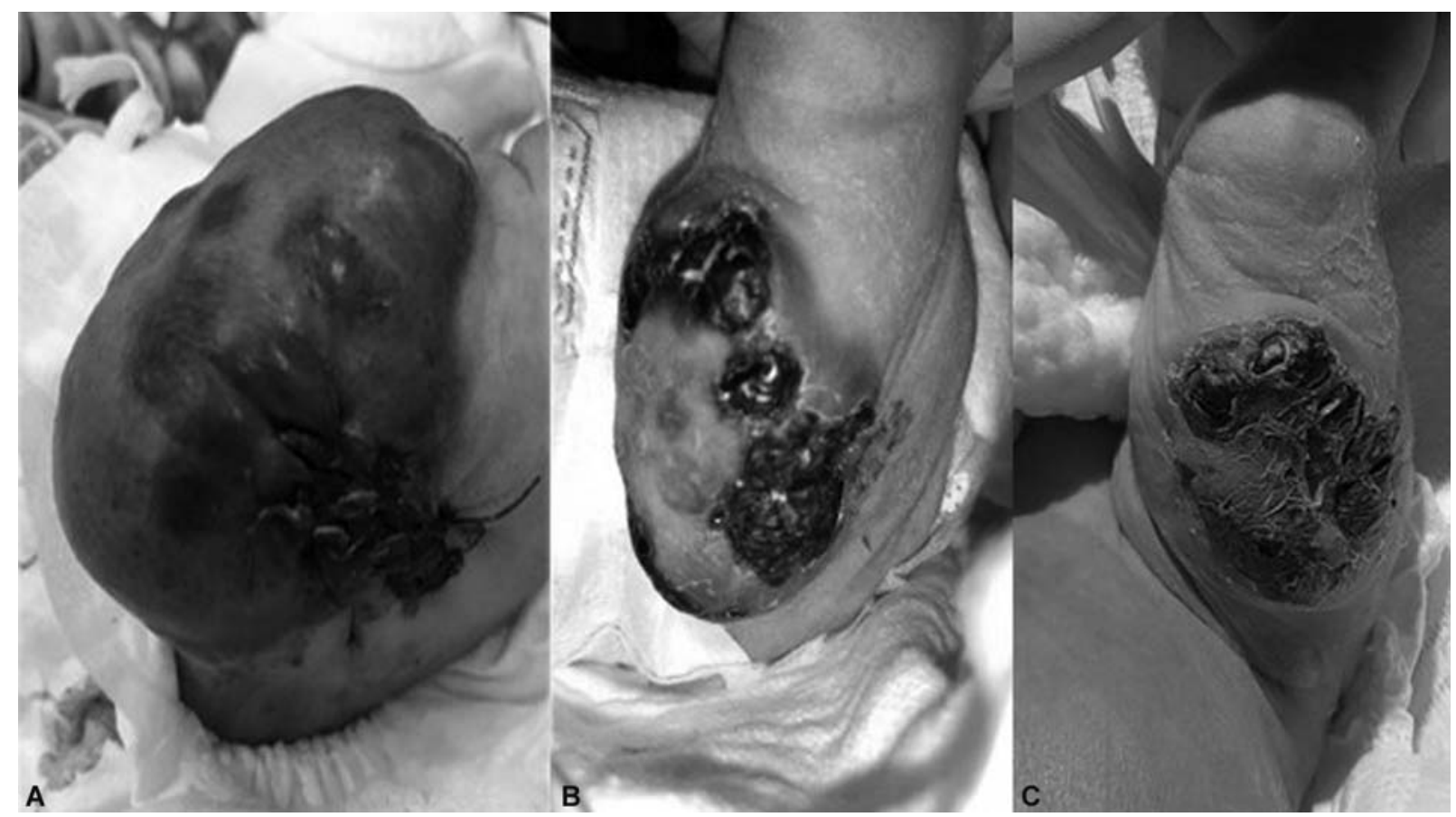

Fig. 2 Progression of the kaposiform hemangioendothelioma lesion during inpatient treatment: (A) postoperative day 1; (B) after 4 weeks of treatment; (C) after 5 weeks of treatment.

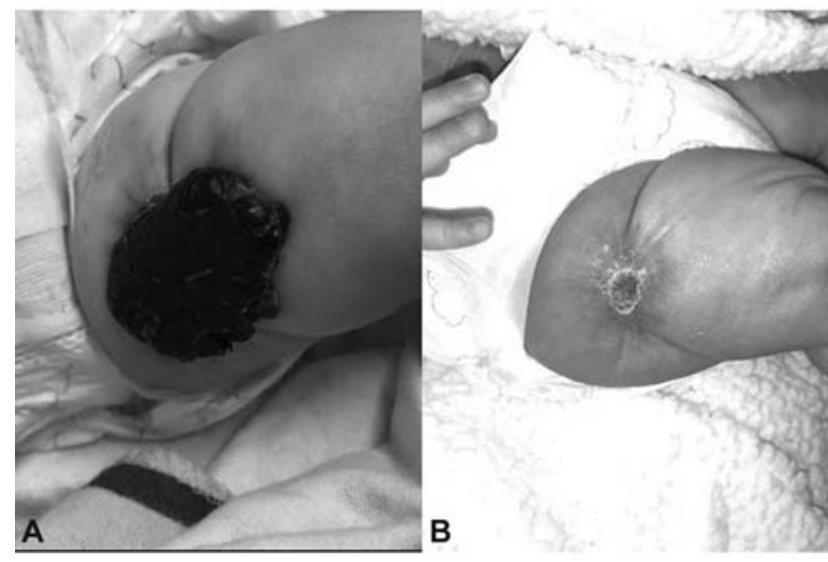

Fig. 3 Resolution of the kaposiform hemangioendothelioma lesion during outpatient treatment: (A) after 2 months of treatment; (B) after 3 months of treatment.

evaluation includes MRI with contrast and surgical biopsy for confirmation.

Prenatal complications can include effusions and multiorgan failure. Long-term outcomes include residual cutaneous effects: pseudoport wine stains with papules, telangiectasias with swelling, and fibrotic subcutaneous infiltrates. ${ }^{4}$ Fifty to seventy percent of patients with KHE develop KMP, a potentially life-threatening consumptive coagulopathy with thrombocytopenia and hypofibrinogenemia, with a reported mortality of up to $30 \%$. Thus, early identification and initiation of treatment are vital. ${ }^{2,5,6}$ However, it should be noted that the use of platelet transfusions in this condition is controversial. In general, because of platelet trapping within the lesion, transfusion is not a recommended treatment unless there is active bleeding or a plan for surgical intervention. ${ }^{7}$ Conversely, preterm infants with severe thrombocytopenia are at risk of development and/or extension of IVH. The infant in the case presented with severe thrombocytopenia in the first hours of life (platelet count $=13 \mathrm{~K} / \mu \mathrm{L}$ ) that contributed to his severe brain injury. He also underwent surgical biopsy of the lesion on day of life 3. Thus, platelet transfusions were given in this case.

Although the first report of KMP in 1940 described this event as occurring as a complication of capillary hemangiomas, further studies have found that this phenomenon occurs exclusively with KHE and tufted angiomas, not with infantile or congenital hemangiomas. ${ }^{8,9}$ Treatment of KMP is largely supportive, with transfusion of blood products and clotting factors while being careful to avoid fluid overload. It is likely that the massive transfusions and infusions, required by the baby in our case to control the symptoms of KMP, contributed to the acute cardiac failure he experienced, a rare complication known as transfusion-associated circulatory overload (TACO). ${ }^{10}$ Infants are identified as an at-risk population for TACO. ${ }^{11}$ However, most infants, even those who receive the same amount of blood products as the infant in our case, will not experience TACO.

Uniform guidelines for neonates affected by KHE are lacking. Thus, many treatment modalities have been tried. Prior to 2016, there were no prospective studies to demonstrate efficacy and safety of these modalities. Historically, treatment of KHE has included high-dose steroids, chemotherapy (e.g., cyclophosphamide), antiplatelet therapy (e.g., aspirin), propranolol, embolization, radiotherapy, and sclerotherapy. ${ }^{12}$ Surgical resection was, historically, considered the gold standard for definitive treatment. However, due to extensive vascular involvement, surgery may not be feasible without significant soft tissue loss and need for 
coverage. In 2013, a consensus-derived recommendation suggested treatment using vincristine with or without corticosteroids. ${ }^{7}$ Vincristine is a chemotherapeutic agent with multiple adverse effects including peripheral neuropathy, retinal toxicity, constipation and rarely vocal cord paralysis/ dysfunction, leukopenia, and anemia. ${ }^{13,14}$ Furthermore, its administration requires central intravenous access requiring prolonged or recurrent hospitalizations for treatment in neonates, and complete remission of lesions remains inconsistent. A recent review found that tumor size decreased in $39 \%$ of patients treated with vincristine. ${ }^{15}$ For these reasons, treatment has turned toward focusing on more target-specific therapy with less side effects and similar efficacy. In the last two decades, sirolimus, an inhibitor of the mammalian target of rapamycin (mTOR), has been used with increasing efficacy for vascular anomalies and rarely reported serious side effects. ${ }^{16}$

Since the 1980s, the phosphoinositide-3-kinase (PI3K)/ Akt pathway has been of interest due to its role in cell metabolism, growth, and survival. Studies have shown this signaling pathway to be critical in regulation of normal vascular proliferation. Extracellular growth factors are transmitted via tyrosine kinase receptors to intracellular PI3K that are further communicated to Akt/protein kinase B. They are then transferred to the mTOR kinase that subsequently activates ribosomal biogenesis and protein synthesis leading to angiogenesis and lymphangiogenesis. Dysregulation of this pathway has been identified as an important mechanism in vascular overgrowth syndromes and vascular anomalies. ${ }^{17,18}$ Originally approved by the Food and Drug Administration in 1999 for the treatment of allograft rejection in transplant patients, sirolimus targets mTOR, leading to downregulation of these angiogenic processes. In 2008, it was utilized for the first time in treatment of a patient with Proteus syndrome and since then, multiple case reports worldwide have shown improvement when treating various vascular anomalies. ${ }^{19,20}$ In 2013, a phase 2 trial was completed to demonstrate the safety and efficacy for sirolimus for nine vascular anomalies, including KHE. ${ }^{16}$ Importantly, the standard dosing in this trial was of $0.8 \mathrm{mg} / \mathrm{m}^{2}$ per dose twice daily with a goal trough of 10 to $15 \mathrm{ng} / \mathrm{mL}$. Of the 61 patients enrolled from 2009 to 2013, a majority (85\%) showed marked improvement in tumor size as well as quality of life; however, none achieved complete remission. For KHE with KMP, 100\% showed partial remission at both 6 and 12 months of treatment. Only two patients required discontinuation of the study due to persistent adverse effects, with the most common toxicities being bone marrow suppression, metabolic derangements (e.g., hypercholesterolemia and hypertriglyceridemia), and gastrointestinal side effects (e.g., vomiting and diarrhea). ${ }^{16}$ These results were further seen in a multicenter retrospective study in 2017 in China, involving 52 patients demonstrating reproducible safety and efficacy of sirolimus for KHE. ${ }^{21}$ Importantly, the most severe adverse effect reported with sirolimus has been immunosuppression including case reports of death due to severe Pneumocystis jirovecii pneumonia in the setting of sirolimus use. ${ }^{22,23}$ Most recently, a multicenter randomized phase 2 study was performed comparing vincristine with sirolimus for first-line treatment of patients with KHE or tufted angiomas complicated with KMP. Enrollment occurred from 2017 to 2020 and utilized standard dosing of sirolimus at $0.8 \mathrm{mg} / \mathrm{m}^{2}$ per dose twice a day. While final results are pending at the time of this report, ample literature supports the potential for sirolimus to replace vincristine as first-line therapy for KHE given the oral formulation, larger therapeutic index, and overall tolerability. ${ }^{15,24}$

While we report successful treatment of KHE with sirolimus, many questions regarding the dosing and monitoring of the drug in neonates remain. Standard dosing of sirolimus at $0.8 \mathrm{mg} / \mathrm{m}^{2}$ per dose twice a day leads to goal trough levels of 10 to $15 \mathrm{ng} / \mathrm{mL} .{ }^{16}$ However, in our patient, this dosing led to supratherapeutic levels that may have unknown complications. Sirolimus is metabolized by the hepatic enzyme CYP3A4. ${ }^{25,26}$ Due to varying maturation of hepatic enzymes in the neonatal period, the bioavailability as well as half-life of the medication may be changed, requiring adjusted dosing. Additionally, infection and inflammation are associated decreased sirolimus clearance due to cytokine-based downregulation of expression and suppressed activity of hepatic and extrahepatic cytochrome P450 systems. ${ }^{27}$ We ultimately achieved goal trough levels with a decreased dose of $0.4 \mathrm{mg} /$ $\mathrm{m}^{2}$ per dose twice a day. Other institutions have reported similar variability and efficacy in neonate dosing with one using $0.8 \mathrm{mg} / \mathrm{m}^{2}$ per dose once daily, another starting at $0.1 \mathrm{mg} / \mathrm{kg}$ per dose once daily, and another at $0.05 \mathrm{mg} / \mathrm{kg}$ per dose twice daily. ${ }^{23,28-30}$ Similarly, trough levels have varied with reports of successful treatment at goal ranges of 2 to $3 \mathrm{ng} / \mathrm{mL}, 4$ to $10 \mathrm{ng} / \mathrm{mL}$, and 10 to $13 \mathrm{ng} / \mathrm{mL}^{29-32}$ As sirolimus becomes an increasingly acceptable oral treatment of KHE, standardization of dosing and acceptable therapeutic trough levels for neonates will require closer attention. Our institution has the experience of successfully treating patients with sirolimus for vascular anomalies, including KHE, and we believe that sirolimus will become an increasingly acceptable and preferred option for treating vascular lesions in the future. Correctly dosed, there is potential for radical improvement in the quality of life and clinical course of neonates with KHE.

\section{Conclusion}

We have presented a complex case of KHE in a neonate complicated by KMP treated with sirolimus. Treatment is initially supportive and aimed at controlling the symptoms of KMP. Attention should be paid to fluid management and control of thrombocytopenia with associated sequelae. Prior to the increasing application of sirolimus, surgical excision was the gold standard for definitive treatment. Sirolimus is increasingly becoming the first-line treatment of KHE. The correct dose of sirolimus in these cases is not clear, but available literature suggests that the current common empiric dose may be too high in many cases.

Conflict of Interest

None declared. 


\section{References}

1 Zukerberg LR, Nickoloff BJ, Weiss SW. Kaposiform hemangioendothelioma of infancy and childhood. An aggressive neoplasm associated with Kasabach-Merritt syndrome and lymphangiomatosis. Am J Surg Pathol 1993;17(04):321-328

2 Croteau SE, Liang MG, Kozakewich HP, et al. Kaposiform hemangioendothelioma: atypical features and risks of Kasabach-Merritt phenomenon in 107 referrals. J Pediatr 2013;162(01):142-147

3 Merrow AC, Gupta A, Patel MN, Adams DM. 2014 revised classification of vascular lesions from the International Society for the Study of Vascular Anomalies: radiologic-pathologic update. Radiographics 2016;36(05):1494-1516

4 Walsh MA, Carcao M, Pope E, Lee KJ. Kaposiform hemangioendothelioma presenting antenatally with a pericardial effusion. J Pediatr Hematol Oncol 2008;30(10):761-763

5 el-Dessouky M, Azmy AF, Raine PA, Young DG. Kasabach-Merritt syndrome. J Pediatr Surg 1988;23(02):109-111

6 Ryan C, Price V, John P, et al. Kasabach-Merritt phenomenon: a single centre experience. Eur J Haematol 2010;84(02):97-104

7 Kasabach HH, Merritt KK. Capillary hemangioma with extensive purpura: report of a case. Am J Dis Child 1940;59(05):1063-1070

8 Sarkar M, Mulliken JB, Kozakewich HP, Robertson RL, Burrows PE. Thrombocytopenic coagulopathy (Kasabach-Merritt phenomenon) is associated with Kaposiform hemangioendothelioma and not with common infantile hemangioma. Plast Reconstr Surg 1997;100(06):1377-1386

9 Silvergleid AJ. Transfusion-associated circulatory overload (TACO). UpToDate. https://www.uptodate.com/contents/transfusion-associated-circulatory-overload-taco\#: : $t$ ext=S\%20Tirnauer\%2C\%20MD-,INTRODUCTION,volume\%20excess\%20or\%20circulatory\%20overload. Accessed Aug 19, 2020

10 Politis C, Wiersum JC, Richardson C, et al. The International Haemovigilance Network Database for the Surveillance of Adverse Reactions and Events in Donors and Recipients of Blood Components: technical issues and results. Vox Sang 2016;111 (04):409-417

11 Shen WC, Liang PC, Wu JF, Hsu CT, Chen HS, Chen HL. Combined transarterial embolization and propranolol as effective treatment for hepatic hemangioma with Kasabach-Merritt syndrome and heart failure in a neonate. Pediatr Neonatol 2017;58(02):191-193

12 Drolet BA, Trenor CC III, Brandão LR, et al. Consensus-derived practice standards plan for complicated Kaposiform hemangioendothelioma. J Pediatr 2013;163(01):285-291

13 Anghelescu DL, De Armendi AJ, Thompson JW, Sillos EM, Pui CH, Sandlund JT. Vincristine-induced vocal cord paralysis in an infant. Paediatr Anaesth 2002;12(02):168-170

14 Ahmed A, Williams D, Nicholson J. Vincristine-induced bilateral vocal cord paralysis in children. Pediatr Blood Cancer 2007;48 (02):248

15 Schmid I, Klenk AK, Sparber-Sauer M, Koscielniak E, Maxwell R, Häberle B. Kaposiform hemangioendothelioma in children: a benign vascular tumor with multiple treatment options. World J Pediatr 2018;14(04):322-329
16 Adams DM, Trenor CC III, Hammill AM, et al. Efficacy and safety of sirolimus in the treatment of complicated vascular anomalies. Pediatrics 2016;137(02):e20153257

17 Vignot S, Faivre S, Aguirre D, Raymond E. mTOR-targeted therapy of cancer with rapamycin derivatives. Ann Oncol 2005;16(04): 525-537

18 Hemmings BA, Restuccia DF. PI3K-PKB/Akt pathway. Cold Spring Harb Perspect Biol 2012;4(09):a011189

19 Hammill AM, Wentzel M, Gupta A, et al. Sirolimus for the treatment of complicated vascular anomalies in children. Pediatr Blood Cancer 2011;57(06):1018-1024

20 Marsh DJ, Trahair TN, Martin JL, et al. Rapamycin treatment for a child with germline PTEN mutation. Nat Clin Pract Oncol 2008;5 (06):357-361

$21 \mathrm{Ji} \mathrm{Y,} \mathrm{Chen} \mathrm{S,} \mathrm{Xiang} \mathrm{B,} \mathrm{et} \mathrm{al.} \mathrm{Sirolimus} \mathrm{for} \mathrm{the} \mathrm{treatment} \mathrm{of}$ progressive kaposiform hemangioendothelioma: a multicenter retrospective study. Int J Cancer 2017;141(04):848-855

22 Russell TB, Rinker EK, Dillingham CS, Givner LB, McLean TW. Pneumocystis jirovecii pneumonia during sirolimus therapy for kaposiform hemangioendothelioma. Pediatrics 2018;141(Suppl 5): S421-S424

23 Ying H, Qiao C, Yang X, Lin X. A case report of 2 sirolimus-related deaths among infants with Kaposiform Hemangioendotheliomas. Pediatrics 2018;141(Suppl 5):S425-S429

24 Adams DM. A study to compare vincristine to sirolimus for treatment of high risk vascular tumors. NIH Study ID NCT02110069. Available at ClinicalTrials.gov: https://clinicaltrials.gov/ct2/show/ record/NCT02110069. Accessed January 5, 2020

25 Brattström C, Säwe J, Jansson B, et al. Pharmacokinetics and safety of single oral doses of sirolimus (rapamycin) in healthy male volunteers. Ther Drug Monit 2000;22(05):537-544

26 Buhaescu I, Izzedine H, Covic A. Sirolimus-challenging current perspectives. Ther Drug Monit 2006;28(05):577-584

27 Mizuno T, Emoto C, Fukuda T, Hammill AM, Adams DM, Vinks AA Model-based precision dosing of sirolimus in pediatric patients with vascular anomalies. Eur J Pharm Sci 2017;109S:S124S131

28 Czechowicz JA, Long-Boyle JR, Rosbe KW, Mathes EF, Frieden IJ, Shimano KA. Sirolimus for management of complex vascular anomalies - a proposed dosing regimen for very young infants. Int J Pediatr Otorhinolaryngol 2018;105:48-51

29 Tribolet S, Hoyoux C, Boon LM, et al. A not so harmless mass: kaposiform hemangioendothelioma complicated by a KasabachMerritt phenomenon. Arch Pediatr 2019;26(06):365-369

30 Wang H, Guo X, Duan Y, Zheng B, Gao Y. Sirolimus as initial therapy for kaposiform hemangioendothelioma and tufted angioma. Pediatr Dermatol 2018;35(05):635-638

31 Schaefer BA, Wang D, Merrow AC, Dickie BH, Adams DM. Longterm outcome for kaposiform hemangioendothelioma: a report of two cases. Pediatr Blood Cancer 2017;64(02):284-286

32 Zaidi SJ, Shaik S, Agrawal C, Cossor W. First intracardiac kaposiform hemangioendothelioma in an infant resolved with sirolimus: a case report. J Pediatr Hematol Oncol 2018;40(07):536-540 